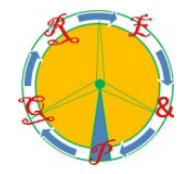

\title{
Non-linear inductor modelling for a DC/DC Buck converter
}

\author{
G. Lullo ${ }^{1}$, D. Scirè ${ }^{1}$ and G. Vitale ${ }^{2}$. \\ ${ }^{1}$ Dipartimento di Energia, ingegneria dell'Informazione e modelli Matematici, Università di Palermo, \\ Viale delle Scienze, Edif.9, 90128 Palermo (Italy), email: giuseppe.lullo(at)unipa.it, daniele.scire91(at)gmail.com \\ ${ }^{2}$ Istituto di Studi sui Sistemi Intelligenti per l'Automazione (ISSIA), Consiglio Nazionale delle Ricerche (CNR), \\ Via Dante Alighieri, n. 12 - 90141 Palermo (Italy), corresponding author, email: gianpaolo.vitale(at)enr.it
}

\begin{abstract}
The paper is focused on the modelling of an inductor to exploit its non-linear behaviour in the roll-off region when it is employed in a DC/DC converter. The model is set up on the basis of experimental data measured in operating conditions, which are fitted to a polynomial curve describing the inductance variations. The analysis of the buck converter, performed by including the proposed model, is validated by experimental tests.
\end{abstract}

\section{Key words}

Inductor, modelling, moderate saturation, roll-off region.

\section{Introduction}

Switch-mode power supplies (SMPS) in step-down and step-up configuration are widely used in many portable applications especially where energy is obtained by renewable sources [1-3]. The optimal design implies that a high power density value is achieved. These circuits use the inductor as an energy reservoir, which is energized by the voltage source and transfers energy to the load kept at constant voltage by a capacitor. The inductor remains a bulky component of the converter since its core is dimensioned to prevent the onset of saturation. This approach raises the size and cost of the inductor[4].

In most of the theoretical studies on the static and dynamic performances of converters, the inductor is considered as a linear device, i.e. a dipole in which the magnetic flux is proportional to the current.In particular the inductor is operated with a constant DC current value and a moderate ripple allowing the hysteresis curve to be considered as linear and the inductance as constant $[5,6]$. Anyway, this jeopardizes the power density since during operation the inductor's capabilities are not fully exploited [7, 8]. Recently the use of inductors working in partial saturation has been considered in literature where it has been assessed that the advantages in using a more compact inductor imply an acceptable amount of losses [9-11].

From the theoretical point of view, if the hypothesis of linearity for the inductor is removed, the value of the inductor varies with the current. During its operation in a $\mathrm{DC} / \mathrm{DC}$ converter, when it is biased with a DC value of the flux with a superimposed ripple, the inductance will experience a variation from a minimum to a maximum during the switching period. For this reason a suitable model is required.

Some models have been proposed in literature. In [12] a first approximation is obtained using Finite Element Analysis (FEA), then the model is verified by comparing the results obtained from the simulation with measurements. Reference [13] proposes a model of magnetic components which integrates a nonlinear model of hysteresis, electro-magnetic windings and thermal behavior in a single model for use in circuit simulation of power electronics systems.

The operating efficiency of the full bridge converters via one and two output inductors was evaluated and analysed in [14], where to take into account the magnetic saturated effects of the core material, a nonlinear inductance model is used. A dynamic model including the effects of saturation, hysteresis and eddy currents for lossy inductors is presented in [15]. In [7] a behavioural analytical model of inductance versus current saturation curve, obtained starting from the data provided by inductors manufacturers, is proposed and the inductor is analytically described by means of an arctangent function. In [16] three different models are described: an average model, a piecewise linearized model and a model based on the Volterra-series expansion.

In this paper a new model of the inductor, based on a polynomial curve fitting of the inductance variation, is proposed. The model is obtained by an experimental set up in which the inductor is DC biased and a flux ripple is superimposed. This approach allows the model to be identified when data provided by manufacturer are lacking or not sufficient. The suitability of the model has been assessed by comparing simulation and experimental data obtained by a buck converter whose inductor has been previously characterized by following the proposed method.

This paper is organized as follows: in section two the behaviour of a DC/DC Buck converter with inductor in moderate saturation is described. Section three is devoted to the inductor characterization and modelling. A DC/DC buck converter implementation is presented in section four and the experimental rig to validate the model is described in section five. Simulation and experimental results are finally given in section six. 


\section{DC/DC buck converter with inductor in moderate saturation}

The scheme of a Buck converter is shown in Figure 1, where the equivalent series resistance (ESR) of the inductor and of the capacitor are neglected.

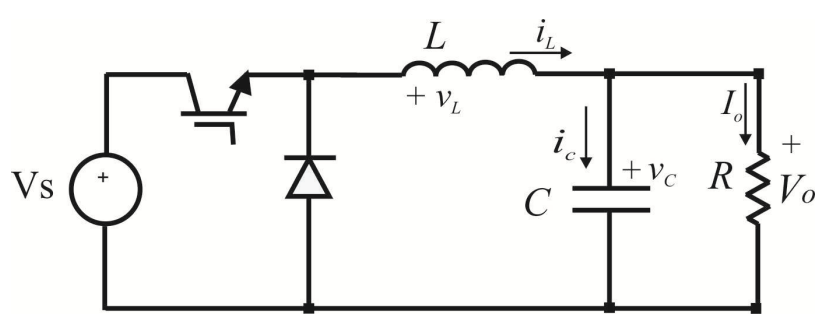

Fig. 1. Buck converter scheme

In Continuous Conduction Mode (CCM), turning on the switch increases the inductor current. When the switch is in "off" state, the inductor current "freewheels" through the diode. During the "on" time the inductor experiences a constant voltage and, if the inductor is linear, the current raises with a constant slope given by $\left(\mathrm{v}_{\mathrm{in}}-\mathrm{v}_{\text {out }}\right) / \mathrm{L}$, whereas during the "off" time the slope is given by $\left(-\mathrm{v}_{\text {out }}\right) / \mathrm{L}$ as shown in Figure 2a. If the average current in the inductor is increased, the weak saturation region is reached at the end of the "on" time. As a consequence, the maximum current will be higher, if compared with the linear case, and the shape will be different according to the variation of the inductance (Figure 2b).

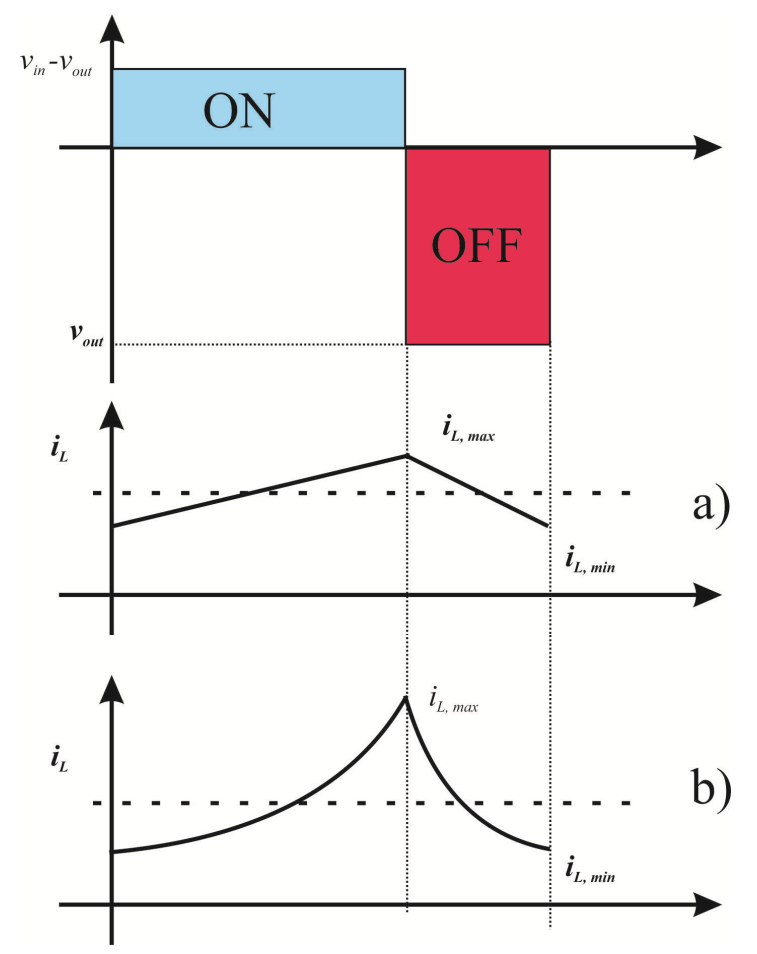

Fig. 2. Inductor current vs. time in a Buck converter in case of: a) inductor operated in linear region, b) inductor operated in moderate saturation.

\section{Inductor characterization.}

\section{A. Linear behaviour}

As it is known, an inductor is characterized by the following relationship between the magnetic flux (or simply flux) and the current:

$$
\phi=i L
$$

where $\phi$ is the flux concatenated with the wires and $L$ the self-inductance (or simply inductance). The voltage vs. current relationship for a linear inductor is obtained by applying the Faraday's law considering the inductance as constant:

$$
v_{L}=\frac{d \phi}{d t}=L \frac{d i_{L}}{d t}
$$

where the voltage and the current are defined according to Figure 3.

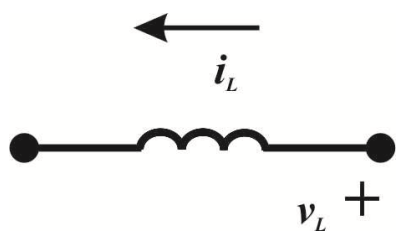

Fig. 3. Inductor dipole representation

\section{B. Commercial power inductors characteristic}

The inductors used in DC/DC converter applications often exhibit an inductance whose value is variable with the current. Figure 4 shows, as an example, the variation of inductance of a set of commercial inductors vs. current, where $L_{R}$ and $I_{R}$ denote the rated values while $L_{o p}$ and $I_{o p}$ are the operating values [17]. As example the inductor B2302M001 corresponds to $L_{R}=2.5 \mathrm{mH}$ and $I_{R}=3 \mathrm{~A}$, it can be noted that the maximum value of the inductance is exhibited for low currents. The greater the current, the smaller is the inductance, which assumes the smallest value (about $30 \%$ of the maximum) when the current reaches 1.4 times of the rated value. In a DC/DC converter the inductor is operated around a DC point. If the ripple of the current around this point is small, the inductor will show a small variation of the flux and equation (2) is still valid. However in the design phase, it implies an oversizing of the inductor as a great part of magnetic material remains unexploited. On the other hand, for larger current ripple around the DC point, an increase of the maximum current will be expected and the variation of the inductance vs. current has to be considered. As a consequence the model described by (2) is no longer valid.

In the curve of the inductance vs. current three regions of operation can be identified: a) the weak saturation region, in which the inductance slightly decreases with respect to $L_{R}$, until about $70 \%$ of $L_{R} ;$ b) the roll-off region, where the inductance swings from values close to $L_{R}$ to values close to the value that represents the saturation $L_{\text {deepsat }} ;$ c) the deep saturation region, where the inductance is much 
lower than about $30 \%$ of $L_{R}$ and approaches the value corresponding to $L_{\text {deepsat }}$.

The extension of the operating points to the roll-off region implies a significantly higher current, flowing through the inductor, compared to the exploitation of the weak saturation region only.

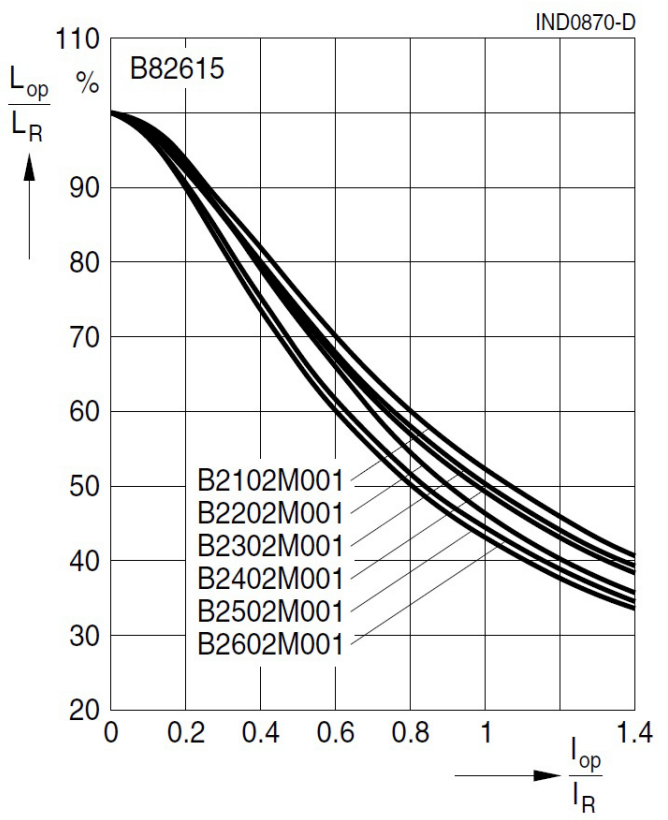

Fig. 4. Inductance vs. current of a commercial inductor

\section{Experimental characterization of the inductor}

In order to identify the function $L=L(i)$ in principle the curves given by manufacturers could be used; unfortunately due to the fabrication tolerances this introduces an appreciable error in the model. For this reason we decided to characterize the inductor experimentally. The measurement circuit is made by a simple Buck converter similar to Figure 1. The DC current if imposed by varying the load, while switching frequency, input/output voltages and duty cycle are optimized in order to limit the current ripple, so to avoid the variation of the inductance. On the basis of the voltage applied to the inductor terminals and of the slope of the current, the inductance is given by:

$$
L(i)=\frac{v_{L}}{\left.\frac{d i_{L}}{d t}\right|_{i=I_{D C}}}
$$

The measurement has been performed on a ring core chokes with iron powder core, with rated inductance of $2.5 \mathrm{mH}$ and rated current of $3 \mathrm{~A}$, setting the DC current equal to: $0.5,1,2,3,4,5$ and $6 \mathrm{~A}$. Then these points have been interpolated by a polynomial curve. The best results has been obtained by a $4^{\text {th }}$ order curve:

$$
L=L_{0}+L_{1} i+L_{2} i^{2}+L_{3} i^{3}+L_{4} i^{4}
$$

with the coefficients given by (5).
Comparing simulated and experimental results (see Figure 5), however it has been noted that the corresponding waveforms are different. It can be explained by a sensitivity analysis of (4). In particular, the sensitivity respect to the coefficients $L_{i}$ is given by the corresponding term of the current (6).

$$
\begin{gathered}
\left\{\begin{array}{l}
L_{0}=3.13 \cdot 10^{-3} \\
L_{1}=-3.21 \cdot 10^{-4} \\
L_{2}=-1.94 \cdot 10^{-4} \\
L_{3}=5.66 \cdot 10^{-5} \\
L_{4}=-4.74 \cdot 10^{-6}
\end{array}\right. \\
\Delta L=\left.\sum_{k} \frac{\partial L(i)}{\partial L_{k}} \Delta L_{k}\right|_{k=0,1, . ., n}=\left.\sum_{k} i^{k} \cdot \Delta L_{k}\right|_{k=0,1, . ., n}
\end{gathered}
$$

Eq. (6) shows that the error on the coefficients with lower index is more relevant at lower current, on the contrary the error on the coefficients with higher index is more relevant at higher current.

A tuning algorithm has been used to adjust the coefficients. This algorithm provides the matching of the coefficients starting from $L_{0}$ obtained by a DC current of $0.5 \mathrm{~A}$ up to $L_{4}$ which is optimized for a DC current of $4 \mathrm{~A}$. The flow chart of the algorithm is shown in Figure 6. On this basis a new set of coefficients (7) has been obtained. These coefficients allow a good fitting of simulated and experimental data as shown in Figure 7.

$$
\left\{\begin{array}{c}
L_{0}=3.50 \cdot 10^{-3} \\
L_{1}=-1.20 \cdot 10^{-4} \\
L_{2}=-1.30 \cdot 10^{-4} \\
L_{3}=3.00 \cdot 10^{-5} \\
L_{4}=-1.90 \cdot 10^{-6}
\end{array}\right.
$$

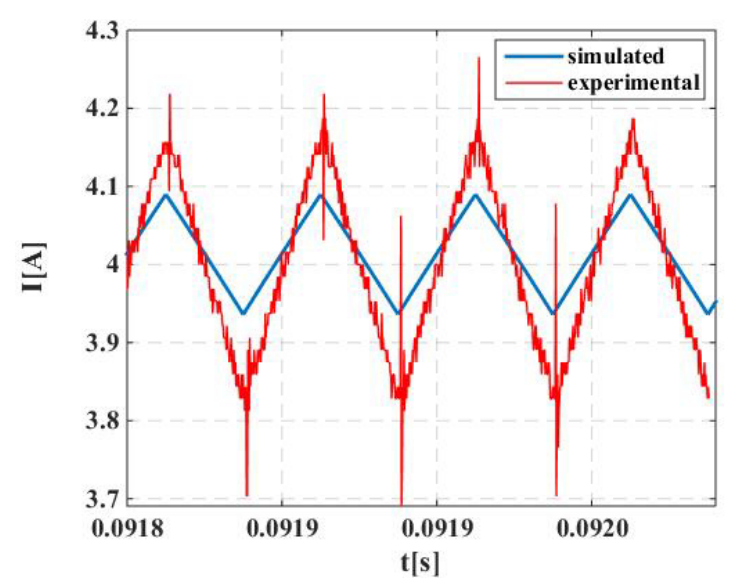

Fig. 5. Simulated and experimental value of the current through the inductor for a DC current of $4 \mathrm{~A}$ before the tuning of the coefficients. 


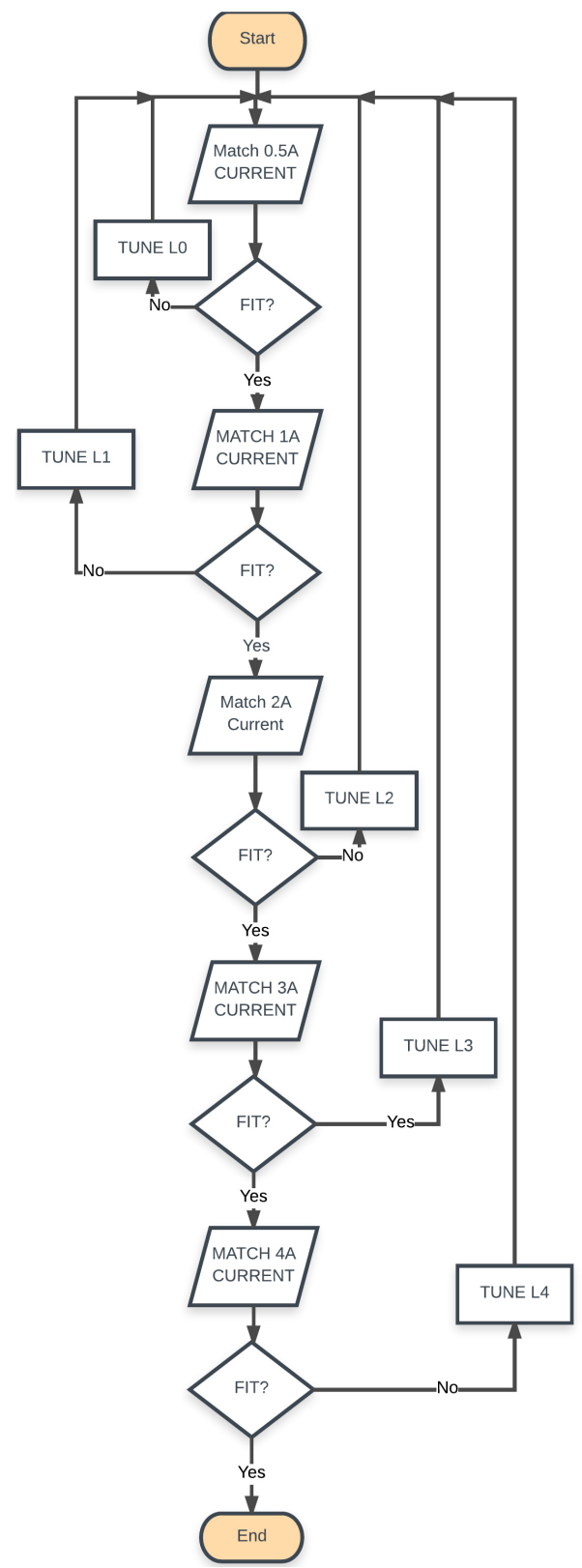

Fig. 6. Flow chart of the tuning algorithm

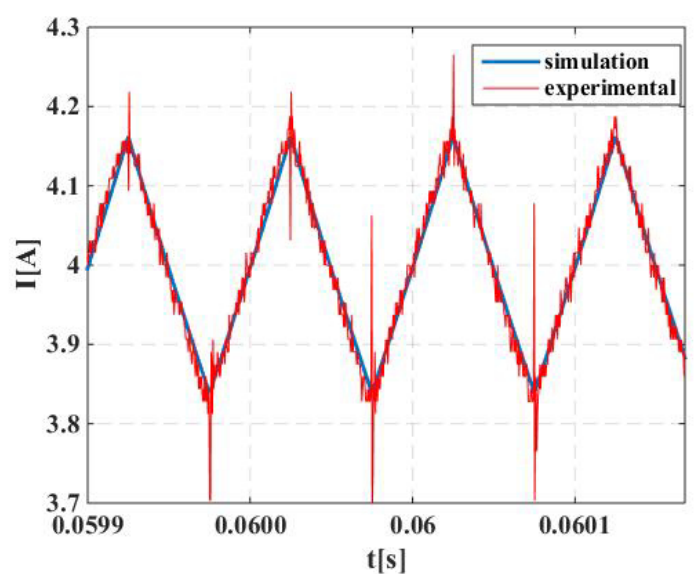

Fig. 7. Simulated and experimental value of the current through the inductor for a DC current of $4 \mathrm{~A}$ after the tuning of the coefficients.
The inductance curve obtained on the basis of the new set of coefficient (7) of polynomial fitting is plotted in Figure 8 . The corresponding characteristics values are: $L_{R}=3.5 \mathrm{mH}, L_{\text {deepsat }}=2.3 \mathrm{mH}, L_{70 \%}=3.14 \mathrm{mH}, L_{30 \%}=2.66 \mathrm{mH}$.

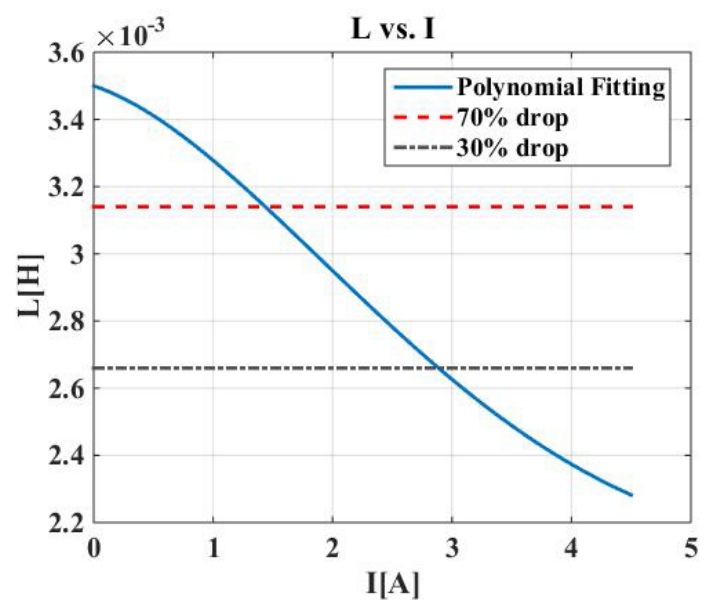

Fig. 8. Inductance vs current curve

\section{Proposed model of the inductor}

The inductor, as described by (4) with coefficients (7), has been modelled to be used in the simulation analysis. The magnetic flux is given by:

$$
\phi=i \cdot L(i)=L_{0} i+L_{1} i^{2}+L_{2} i^{3}+L_{3} i^{4}+L_{4} i^{5}
$$

On the basis of the magnetic flux, eq. (8) is solved in recursive form:

$$
i=\frac{\phi}{L_{0}}-\frac{L_{1}}{L_{0}} i^{2}-\frac{L_{2}}{L_{0}} i^{3}-\frac{L_{3}}{L_{0}} i^{4}-\frac{L_{4}}{L_{0}} i^{5}
$$

with the constraint:

$$
\phi=\int v d t<\max \{i \cdot L(i)\}
$$

This last condition imposes that the horizontal line of the flux must intersect the curve sketched in Figure 9 so that eq. (9) admits a solution. The solution used in simulation lies on the left of the maximum.

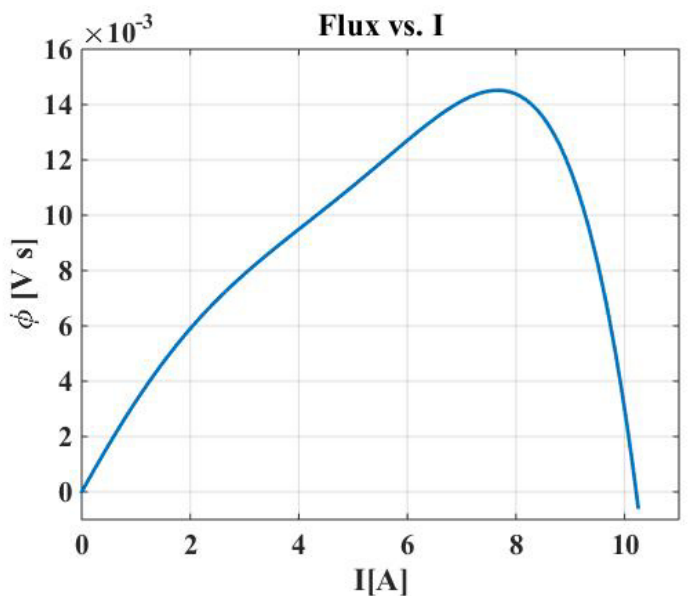

Fig. 9. Flux curve, given by $i \cdot L(i)$. 
The implementation of (9) in Simulink ${ }^{\circledR}$ environment is shown in Figure 10.

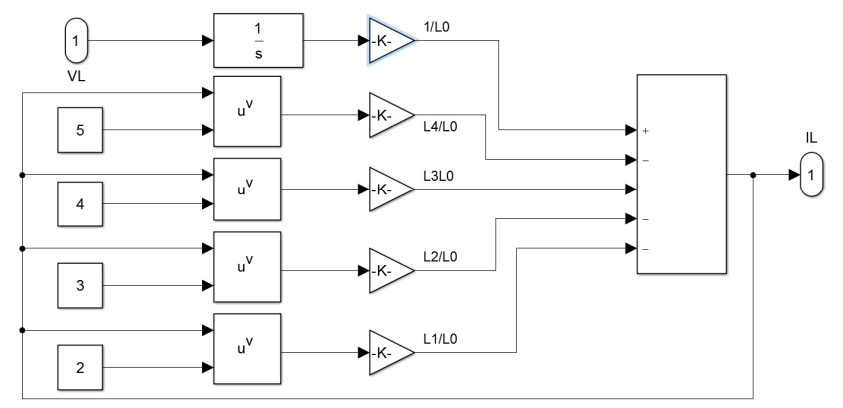

Fig. 10. Implementation of eq. (9) in Simulink ${ }^{\circledR}$ environment

\section{DC/DC buck converter implementation.}

The DC/DC buck converter has been implemented in Simulink ${ }^{\circledR}$ environment following the approach described in [18]. This approach does not require a specific circuit simulator and it is faster than using conventional circuit simulators, in addition it takes into account the parasitic effects of inductors and capacitors. Instead of a linear inductor, the model of Figure 10 has been adopted.

In addition, to validate the simulation results, the circuit has been built in hardware form. The list of the components used for the experimental circuit is summarized in table I.

TABLE I. : COMPONENTS OF THE DC/DC BUCK CONVERTER

\begin{tabular}{|c|c|c|c|}
\hline $\begin{array}{l}\text { electrical } \\
\text { symbol }\end{array}$ & $\begin{array}{l}\text { Rated } \\
\text { value }\end{array}$ & Supplier & code \\
\hline $\mathrm{L}$ & $\begin{array}{l}\mathrm{I}_{\mathrm{R}}=3 \mathrm{~A}, \\
\mathrm{~L}_{\mathrm{R}}=2.5 \mathrm{mH}\end{array}$ & Epcos & B82615-B2302M \\
\hline $\mathrm{C}$ & $100 \mu \mathrm{F}$ & & \\
\hline $\mathrm{T}$ & $\begin{array}{l}\mathrm{VDSS}=100 \mathrm{~V} \\
\mathrm{R}_{\mathrm{DS}}(\text { on })= \\
0.036 \Omega \\
\mathrm{ID}=42 \mathrm{~A}\end{array}$ & $\begin{array}{l}\text { International } \\
\text { Rectifier }\end{array}$ & $\begin{array}{l}\text { HEXFET } ® \text { Power } \\
\text { MOSFET } \\
\text { IRFP150N }\end{array}$ \\
\hline $\mathrm{D}$ & $\begin{array}{l}I F(A V)=12 \mathrm{~A} \\
V_{\text {RRM }}=600 \mathrm{~V} \\
\mathrm{t}_{\mathrm{rr}}(\max )= \\
25 \mathrm{~ns}\end{array}$ & $\begin{array}{l}\text { ST } \\
\text { Microelectronics, } \\
\text { Inc. }\end{array}$ & $\begin{array}{l}\text { Turbo } 2 \text { ultrafast } \\
\text { high voltage } \\
\text { rectifier } \\
\text { STTH12R06DI }\end{array}$ \\
\hline
\end{tabular}

\section{The test rig}

The test rig is composed of a power supply, the DC/DC converter under test, the resistor load, a digital multimeter, an oscilloscope equipped with voltage and current sensors to acquire the duty cycle, the output voltage and the current in the inductor of the DC/DC converter. The main components of the experimental rig are summarized in table II.
TABLE II. COMPOSITION OF THE EXPERIMENTAL RIG

\begin{tabular}{lll}
\hline supplier & function & Model \\
\hline $\begin{array}{l}\text { TDK- } \\
\text { Lambda }\end{array}$ & Power Supply & $\begin{array}{l}\text { TDK GEN600V- } \\
\text { 5.5A }\end{array}$ \\
Agilent & $\begin{array}{l}\text { Signal } \\
\text { generator }\end{array}$ & 33521A \\
& $\begin{array}{l}\text { Resistor } \\
\text { passive Load }\end{array}$ & $\begin{array}{l}\text { RS 136-238 200W } \\
\end{array}$ \\
& $\begin{array}{l}\text { Electronic } \\
\text { Load }\end{array}$ & SLH 500V-6A \\
Sorensen & Digital & DMM4050 61/2- \\
& Multimeter & Digit \\
Tektronix & Oscilloscope & MSO6104A \\
\hline
\end{tabular}

\section{Results}

\section{A. Model validation}

The model has been validated comparing simulation and experimental data of the inductor current and of the output voltage of the converter. Figures $11 \mathrm{a}$ and $11 \mathrm{~b}$ show the shape of the current flowing through the inductor in case of small and large ripple respectively. Figure 11a has been obtained with a supply voltage of $30 \mathrm{~V}$, a switching frequency of $20 \mathrm{kHz}$, duty cycle equal to 0.5 and a DC current of $2 \mathrm{~A}$; it can be noted that with a ripple of about $200 \mathrm{~mA}$ the shape of the current is the well-known triangular waveform.

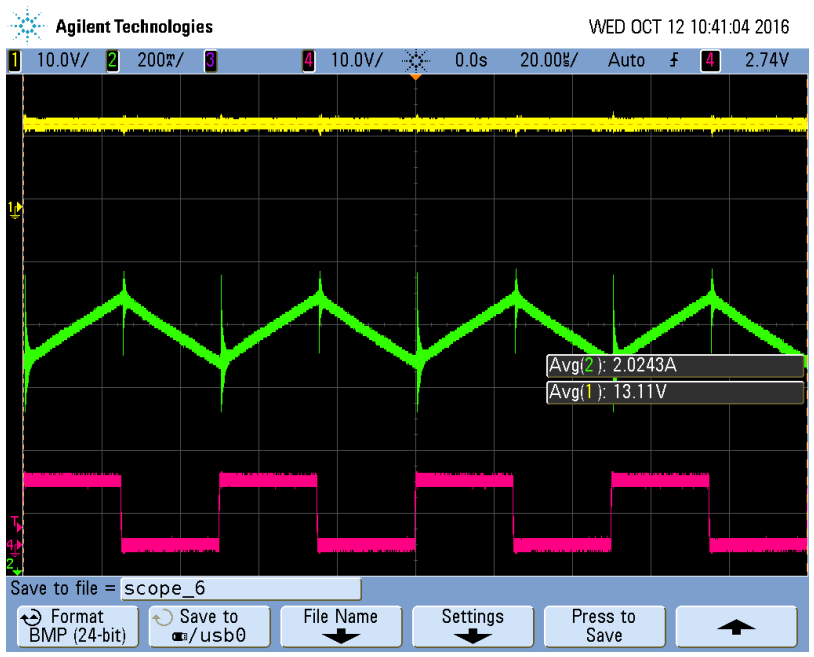

Fig. 11a. Experimental waveforms measured in the DC/DC converter with small ripple: output voltage (top), inductor current (middle), duty cycle (bottom)

The waveforms of Figure $11 \mathrm{~b}$ have been obtained with the same DC current but, the switching frequency has been lowered to $3 \mathrm{kHz}$ and the supply voltage has been increased to $70 \mathrm{~V}$, maintaining the duty cycle of 0.5 . This causes the large ripple and the peaks on the current. These test conditions have been adopted to validate the model. The results are shown in the following Figures. 


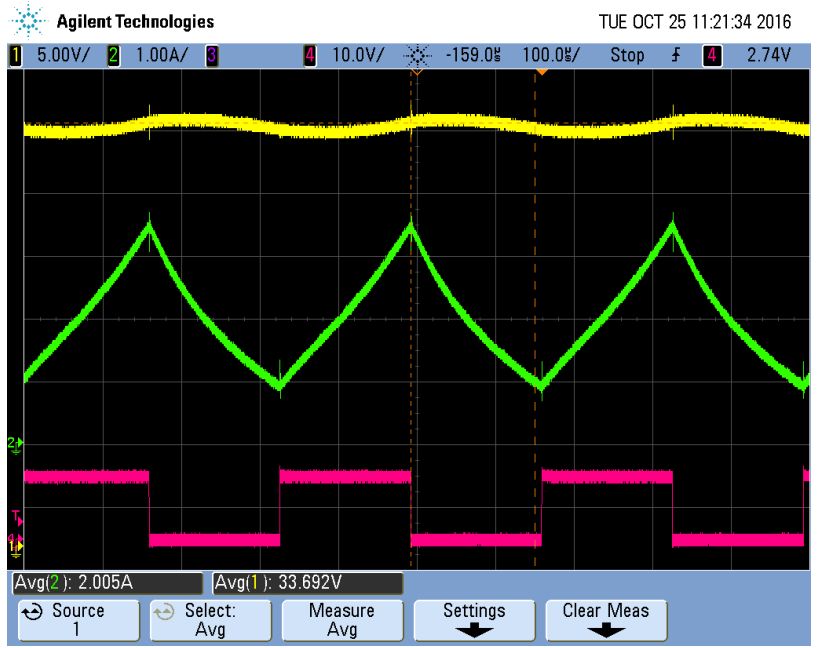

Fig. 11b. Experimental waveforms measured in the DC/DC converter with high ripple: output voltage (top), inductor current (middle), duty cycle (bottom).

The experimental and simulated current are shown in Figure 12 and the relative error is shown in Figure 13. It can be noted that in the worst case the error in a switching period is lower than $13 \%$.

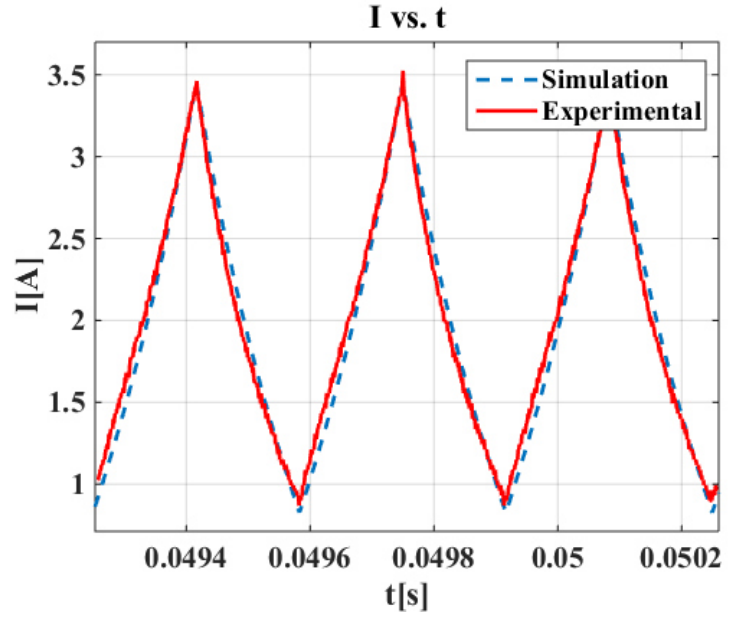

Fig. 12. Simulation and experimental data of the current flowing through the inductor.

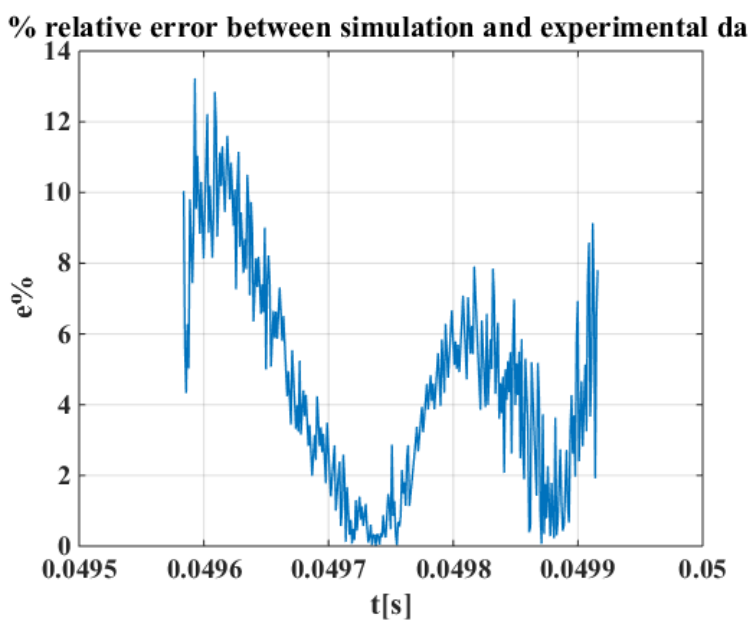

Fig. 13. Percentage relative error in the inductor current comparing simulation and experimental data
The experimental and simulated output voltage are shown in Figure 14. In this case a good agreement can be noted as well.

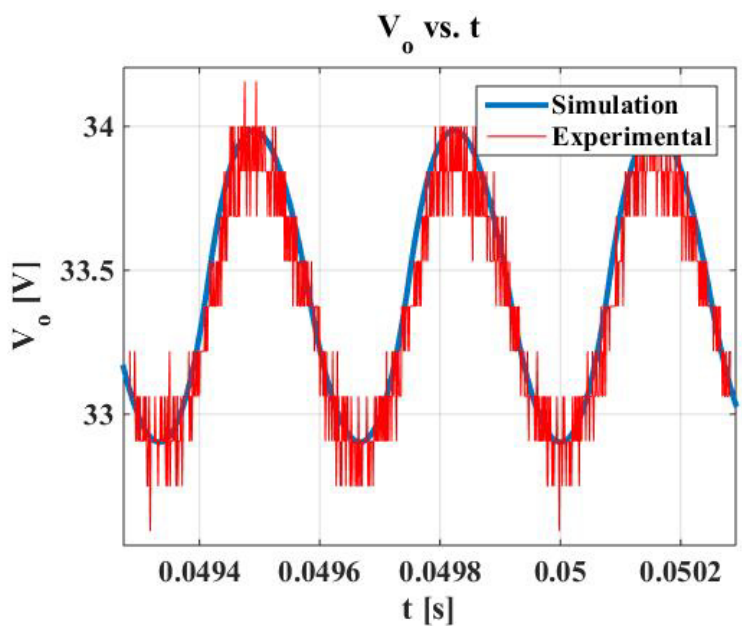

Fig. 14. Comparison of the simulation and experimental data for the output voltage

\section{B. Static Gain}

The static gain, defined as the ratio of the output voltage $V_{0}$ and the input voltage $V_{s}$ has been evaluated in simulation considering the same DC point with a linear inductor whose value is equal to $L_{o}$ (Figure 15a) and with the inductor modelled by eq. (8) (Figure 15b). The switching frequency is equal to $6 \mathrm{kHz}$ and the supply voltage is equal to $70 \mathrm{~V}$. In an ideal case the Buck converter should have a gain equal to the duty cycle $D$. It can be noted that in both cases the intersection of the surface with a plane at constant current gives a straight line for low currents whereas it is influenced by a drop voltage on the parasitic parameters increasing the current. In any case the gain does not differ significantly in case of linear inductor and non-linear one, as a matter of fact the maximum error is equal to $2.5 \cdot 10^{-3} \%$.

\section{Gain vs. D, I (linear inductor)}

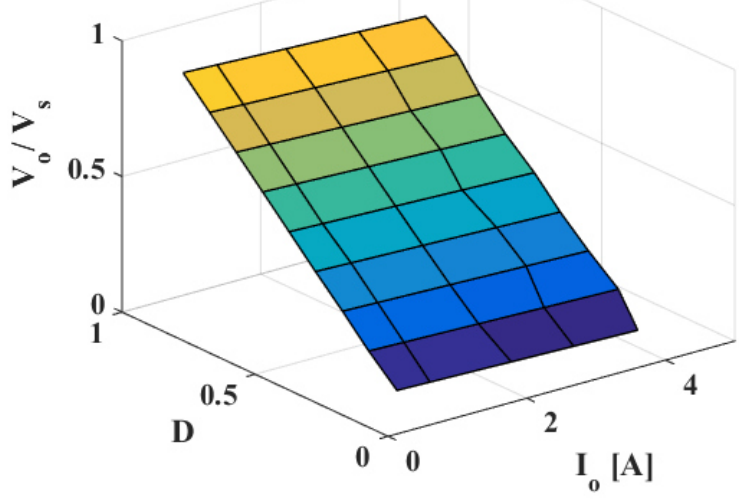

Fig. 15a. Static gain of the Buck converter adopting a linear inductor 


\section{Gain vs. D, I (non-linear inductor)}

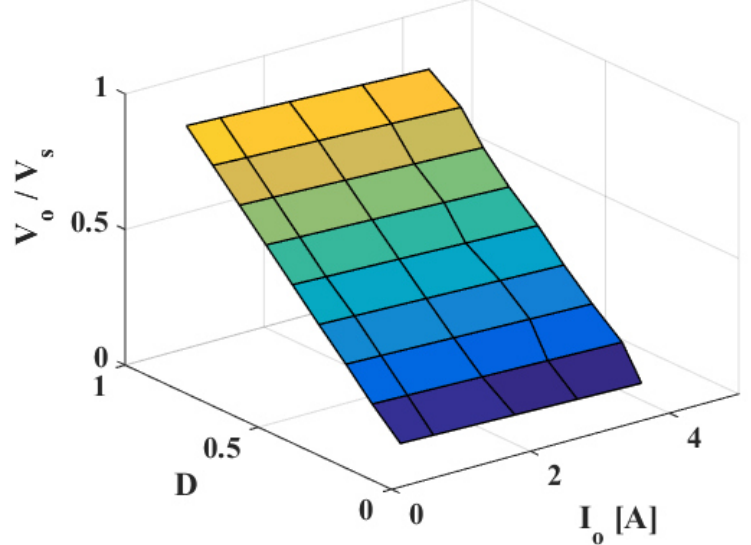

Fig. 15b. Static gain of the Buck converter adopting an inductor operated in moderate saturation

\section{Step response}

The simulated step response has been analysed in both cases, i.e. when the DC/DC converter is operated with a small ripple (obtained increasing the switching frequency to $20 \mathrm{kHz}$ ) and with a large ripple (the inductor is operated in roll-off region). The step has been obtained by varying the load resistance from $70 \Omega$ to $11 \Omega$. The current flowing through the inductor and the output voltage when the ripple is small are respectively plotted in Figure 16 and in Figure 17. In this last case the settling time (evaluated in a range of $5 \%$ ) is equal to $3.47 \mathrm{~ms}$. The initial voltage is equal to $34.3 \mathrm{~V}$ whereas the final voltage is equal to $32.8 \mathrm{~V}$. The initial ripple on the voltage is equal to $0.017 \mathrm{~V}$ and the final value is equal to $0.031 \mathrm{~V}$.

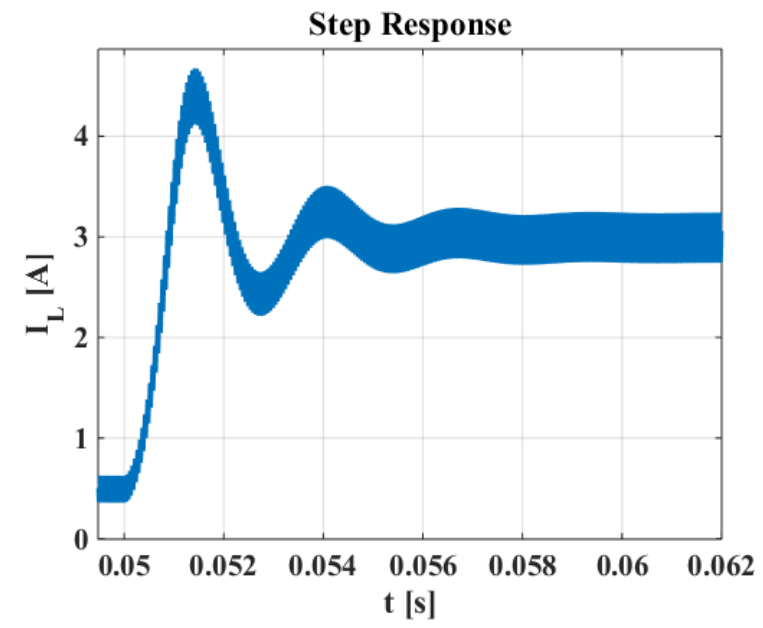

Fig. 16. Inductor current step response with a small ripple

Figure 18 and 19 show the current through the inductor and the output voltage with large ripple obtained lowering the switching frequency to $6 \mathrm{kHz}$. The settling time of the output voltage (evaluated in a range of $5 \%$ ) is equal to 2.62 $\mathrm{ms}$. The initial voltage is equal to $34.3 \mathrm{~V}$ whereas the final voltage is equal to $32.8 \mathrm{~V}$. The initial ripple on the voltage is equal to $0.19 \mathrm{~V}$ and the final value is equal to $0.34 \mathrm{~V}$. Comparing Figures 16 and 18 it can be noted that the increased ripple implies a higher current peak in the inductor as expected.

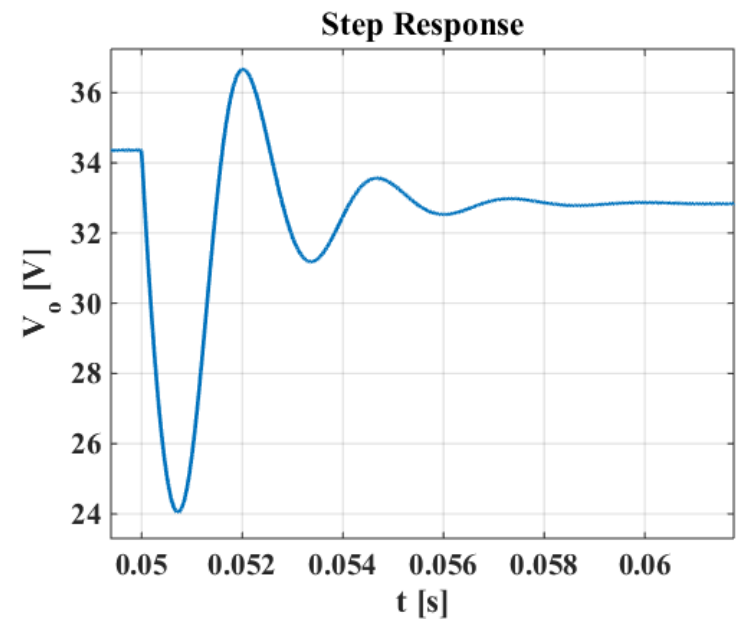

Fig. 17. Output voltage step response with a small current ripple on the inductor.

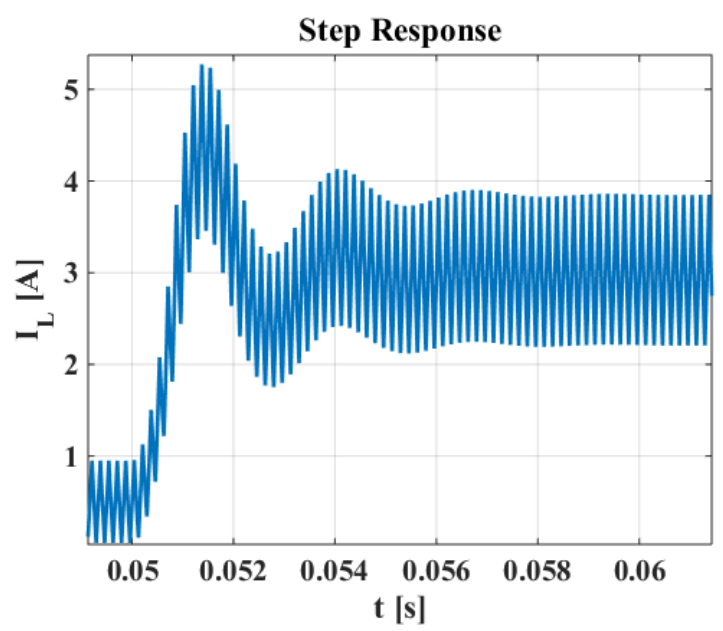

Fig. 18. Inductor current step response with large ripple

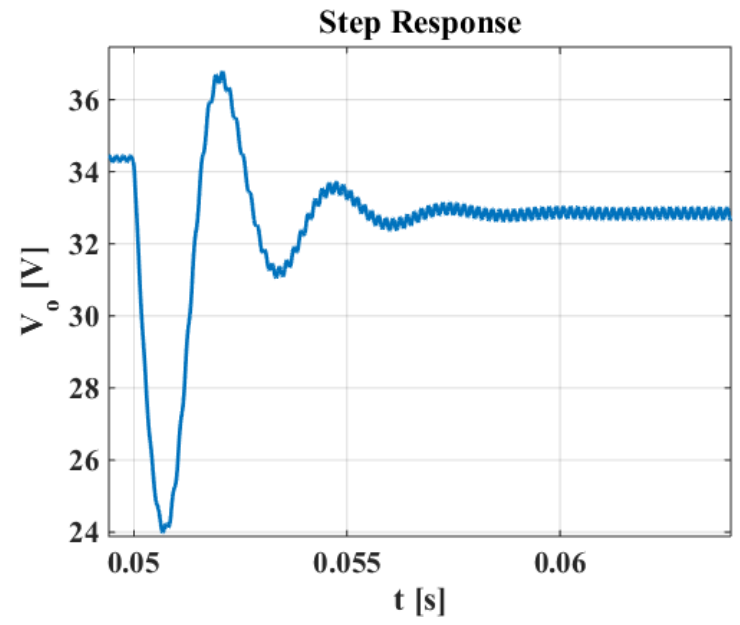

Fig. 19. Output voltage step response with large current ripple on the inductor.

\section{Conclusion}

The exploitation of roll-off region of the inductor in a DC/DC Buck converter has been analysed by a suitable model. The non-linear model of the inductor in a DC/DC 
Buck converter has been implemented and verified experimentally.

From the analysis of the performance it has been noted that the operation in roll-off region does not influence the static gain of the converter. The exploitation of the roll-off region makes the dynamic response faster but causes an higher ripple on the output voltage and a higher peak of the current in the inductor.

Moreover, the exploitation of the roll-off region allows either the switching frequency to be lowered obtaining a reduction of the switching losses or the inductor to be designed with a smaller value of the inductance increasing the power-density of the converter.

On the other hand, a current control loop is recommended to avoid that a current peak in the inductor could damage the power switch or the diode.

\section{Acknowledgement}

This paper has been funded by the research project: RITmare, Ricerca ITaliana per il mare (Italian Research for the sea) CUP:B91J11000740001.

\section{References}

[1] Palma L, Todorovic MH, Enjeti P. Design considerations for a fuel cell powered DC-DC converter for portable applications. 21 st Annual IEEE Applied Power Electronics Conference and Exposition, March 19-23, 2006; 1263-1268.

[2] Vazquez MJ, Marquez JMA, Manzano FS. A methodology for optimizing stand-alone PV-system size using parallelconnected DC/DC converters. IEEE Transactions on Industrial Electronics 2008; 55(7): 2664-2673.

[3] Yuan L, Qu G. Analysis of energy reduction on dynamic voltage scaling-enabled systems. IEEE Transactions on Computer-Aided Design of Integrated Circuits and Systems 2005; 24(12):1827-1837.

[4] L. Milner, G. Rincon-Mora, "Small saturating inductors for more compact switching power supplies", IEEJ transactions on electrical and electronics engineering, trans 2012; 7; 69-73.

[5] N. Mohan, Power Electronics A First Course, John Wiley \& Sons, Inc. United States of America, 2012.

[6] S. Ang, A. Oliva, Power Swiching Converters, CRC Press, Taylor and Francis Group, Boca Raton, FL 2011.

[7] G. Di Capua, N. Femia, "A Novel Method to Predict the Real Operation of Ferrite Inductors With Moderate Saturation in Switching Power Supply Applications", IEEE Transactions on Power Electronics, year: 2016, Volume: 31, Issue: 3.

[8] G. Di Capua, N. Femia, K. Stoyka, "Power magnetics volume and weight reduction in aerospace power supply units", 2016 IEEE 17th Workshop on Control and Modeling for Power Electronics (COMPEL), Trondheim, Norway, 27-30 June 2016.

[9] R. A. Salas and J. Pleite, "Simulation of the saturation and air-gap effects in a pot Ferrite Core with a 2-D finite element model," IEEE Trans. Magnet., vol. 47, no. 10, pp. 4135-4138, Oct. 2011.

[10] R. A. Salas and J. Pleite, "Equivalent electrical model of a Ferrite Core inductor excited by a square waveform including saturation and power losses for circuit simulation," IEEE Trans. Magn., vol. 49, no. 7, pp. 4257-4260, Jul. 2013.

[11] A. Stadler, T. Stolzke, and C. Gulden, "Nonlinear power inductors for large current crest factors," in Proc. Eur. Power Convers. Intell. Motion Conf., May 2012, pp. 1548-1553.

[12] Salas R, Pleite J, Olias E, Barrado A. Nonlinear saturation modelling of magnetic components for circuit simulation. IEEE International Magnetics Conference, May 2006; 993.
[13] Wilson PR, Ross JN, Brown AD. Simulation of magnetic component models in electric circuits including dynamic thermal effects. IEEE Transactions on Power Electronics 2002; 17:55-65.

[14] Wang JB, Li R, Chen J. Efficiency comparison of full bridge converters in considered magnetic saturation. IEEE Industrial Electronics Conference, November 2008; 717-722.

[15] Chapman PL, Sudhoff SD. Dynamic lossy inductor model for power converter simulation. Applied Power Electronics Conference, March 2002; 137-143.

[16] R. A. Mastromauro, M. Liserre, A. Dell'Aquila, "Study of the Effects of Inductor Nonlinear Behavior on the Performance of Current Controllers for Single-Phase PV Grid Converters, IEEE trans on Ind. Electr. Vol. 55, n. 5, May 2008.

[17] https://en.tdk.eu/tdk-en/530144/products/productcatalog/emc-components/power-line-chokes--epcos-

[18] G. Vitale, "Analysis of DC/DC converters by mean node voltage method", Renewable Energy and Power Quality Journal (RE\&PQJ) ISSN 2172-038 X, No.13, April 2015. 